\section{Digital revolution}

A worldwide name in image-assisted diagnostics, MyRay is the future of digital imaging, according to the UK supplier RPA Dental Equipment Ltd.

Using the latest technologies and techniques MyRay, has created some of the profession's leading designs, including the Hyperion X9, Hyperion X5 and RXDC X-ray unit with Hypersphere technology.

While all of the imaging equipment available offers something unique to dentists and their dental teams, each MyRay digital imager is designed using the same set of principles - that is to create a safe solution with low dosage, ultra-sharp imaging and easy to use functions.

To find out more about the specific applications and design features of the various products, get in touch with RPA Dental. As the UK supplier of MyRay equipment, RPA Dental will be able to help with the selection process before delivering and installing the equipment and providing staff training.

More information is available by visiting www.rpadental.net or calling 08000933975.

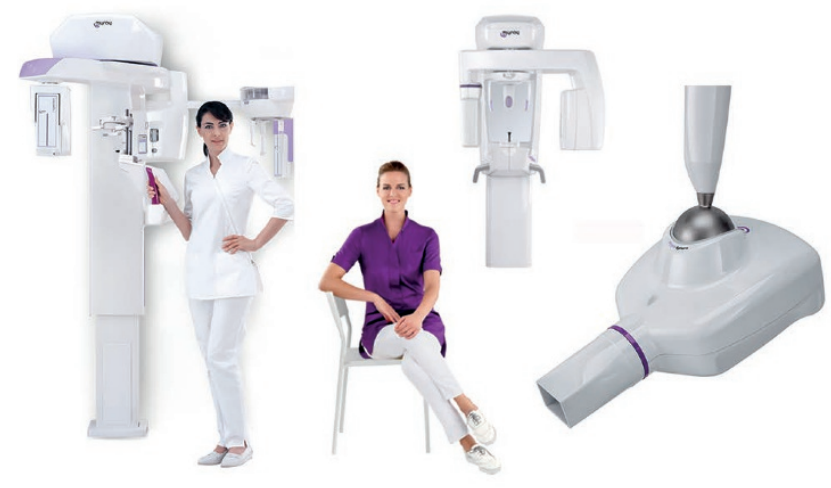

\section{New ortho-toothbrush wows at Dental Showcase}

Delegates at the BDIA Dental Showcase flocked to see Curaprox's brand-new Hydrosonic Ortho toothbrush, designed for use during and after orthodontic treatment.

The newest addition to the Curaprox range of sonic toothbrushes uses the latest technology to provide two-fold cleaning results - mechanical and hydrodynamic - and offers effective cleaning between the teeth, braces, brackets and retainers thanks to the CURACURVE bend and CUREN bristles.

Delegates were also treated to demonstrations of the $\mathrm{Be}$ You line of whitening toothpastes available in six original flavours and colours, and Black Is White whitening range with activated carbon.

More information is available by calling 01480862084 , emailing info@curaprox.co.uk or by visiting www.curaprox. co.uk.

\section{Delegates gain crucial insight from dental agency}

Recruitment and its impact on dental businesses has been a recurring theme this year at key events and the recent BDIA Dental Showcase 2018 was no different.

Leading agency Dental Elite was present to provide answers to some of the profession's most burning questions.

Co-founder of Dental Elite Luke Moore said: 'Over the course of the Showcase we met with a number of dental professionals to discuss the impact of current market trends on sales and acquisitions, finance and recruitment.

'It was a great platform to liaise with existing and new clients, and meant we were able to provide much-needed advice.'

More information can be obtained by contacting Dental Elite via its website www.dentalelite.co.uk or by emailing info@ dentalelite.co.uk or calling 01788545900.

\section{Fast delivery, enhanced treatment and excellent results}

For faster, better treatments with outstanding aesthetic results, look no further than the Z1 implant system.

Developed following considerable research and well-proven technology, Z1 is a tissue level implant system that combines zirconia and pure titanium into one seamless component.

The Z1 implant system features a unique zirconia collar, which protects the crestal bone and the gingiva by acting like an antibacterial shield for optimal soft-tissue management, primary stability and osseointegration.

Working at tissue level, the Z1 implant system offers clinicians good visibility and easy accessibility to components. It has a success rate of $98.6 \%$, but one of the main advantages to both practitioners and patients is that it can be placed with one-stage surgery.

Using the Z1 implant system enables clinicians to offer quick delivery, which not only optimises chair time but is also less time consuming and more comfortable for patients.

With the added bonus of immediate aesthetic results, the $\mathrm{Z1}$ system is an appealing treatment option that is sure to meet patients' expectations.

For more information, visit Dental Express at www.dental-express. co.uk, or call 08007076212 .

To learn more about the Z1 implant, visit http://zlimplants.co.uk/ and see the full range of implants at http://dental.tbr-implants.com/en/.

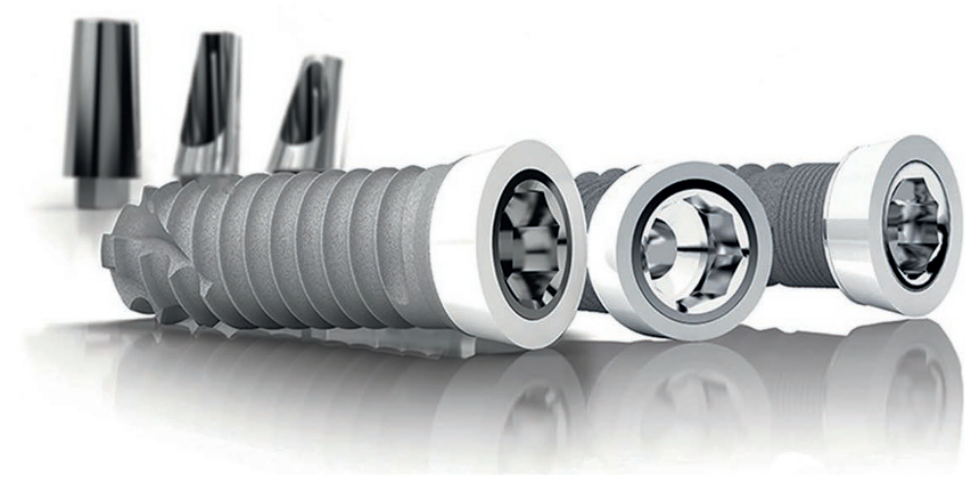

